\title{
The relationship of motor development with sensory processing among infants born very preterm: a prospective case-control study
}

\author{
Özgün Kaya Kara ${ }^{1 \oplus}$, Sedef Şahin ${ }^{2 \oplus}$, Hasan Atacan Tonak ${ }^{1 \oplus}$, Mutluay Arslan ${ }^{3 \oplus}$, \\ Barkın Köse ${ }^{2 \oplus}$, Koray Kara ${ }^{4}$ \\ ${ }^{1}$ Department of Physiotherapy and Rehabilitation, Akdeniz University Faculty of Health Sciences, Antalya; ${ }^{2}$ Department of \\ Occupational Therapy, Hacettepe University Faculty of Health Sciences, Ankara; ${ }^{3}$ Department of Child Neurology, University of Health \\ Sciences Gülhane Training and Research Hospital, Ankara; ${ }^{4}$ Department of Child and Adolescent Psychiatry, University of Health \\ Sciences Antalya Training and Research Hospital, Antalya, Turkey.
}

\begin{abstract}
Background. Little is known about the relationship between sensory processing and motor development in very preterm infants. The purpose of this study was to explore the relationship of motor development with sensory processing among such infants with developmental delay and those who had typical development at the ages of 8 and 12 months.
\end{abstract}

Methods. This prospective case-control study included 61 preterm infants (31 males, 30 females, mean gestational age: 29.1 weeks). The infants had a gestational age of 32 weeks or less and a current corrected age of 8 months, and they had spent at least 15 days in the neonatal intensive care unit. Motor development was assessed with the Neuro-sensory Motor Developmental Assessment (NSMDA), and sensory processing was evaluated with the Test of Sensory Functions in Infants (TSFI).

Results. There were very strong positive correlations between the gross and fine motor scores of the NSMDA and the TSFI's subdomain scores and total scores $(\mathrm{r}=0.85-0.93, \mathrm{p}<0.001)$. There were also very strong negative correlations between the functional level according to the NSMDA and the subdomain scores and total scores of the TSFI $(\mathrm{r}=-0.89-0.94, \mathrm{p}<0.001)$.

Conclusions. The results show that sensory processing and motor development are related parts of the development of very preterm infants. In the early rehabilitation process, therapists should comprehensively take motor and sensory development into consideration.

Key words: preterm, infant, sensory processing, motor, development.

Neonatal Intensive Care Units (NICUs) are crucial for supporting vital functions and decreasing the rates of neonatal morbidity and mortality. ${ }^{1}$ On the other hand, the special care procedures in the NICU have adverse effects on the short and long-term development of infants. ${ }^{2,3}$ The NICU's environment consists of many stressors for preterm infants, who are

凶 Özgün Kaya Kara

ozgun_kaya@yahoo.com

Received 6th January 2021, revised 1st March 2021, 8th March 2021, accepted 16th March 2021. subjected to excessive sensory stimuli such as loud sounds, bright lights, and painful medical procedures. ${ }^{4}$ These excessive stimuli during a key period in the brain's development might affect the physiological responses of infants and cause negative changes in motor, neurological, and sensory development.-7 The reason for this is a lack of inhibitory control for selecting, controlling, and processing sensory stimuli in the developing premature brain. ${ }^{8,9}$ Therefore, the relationship between the NICU and premature birth might set off a chain of adverse events that could lead to learning difficulties and sensory and motor dysfunction. ${ }^{10-12}$ 
Sensory processing is the innate ability to interpret and process sensory inputs and to produce the most appropriate response to the environment. ${ }^{8,9}$ Inadequate sensory processing may contribute to a sensory processing disorder. ${ }^{3,8}$ This disorder involves difficulties in processing and transforming the sensory information used for the regulation of physiological, motor, and emotional or attentional responses in the organization of behavior. ${ }^{13}$ This may result in excessive or insufficient responses to sensory stimuli in the child. ${ }^{14}$

Atypical sensory behaviors affect a child's participation in daily living activities, ${ }^{14}$ which may cause a delay in developmental milestones. ${ }^{15,16} \quad$ Therefore, processing sensory inputs correctly is essential in normal neurodevelopment. ${ }^{15,16}$ Particularly, impairments in the inputs of the vestibular, proprioceptive, and tactile sensory systems may cause problems in producing adaptive behavior, movement coordination, and the development of postural control and motor development. ${ }^{5}$ Sensory processing disorder affects 39 to $52 \%$ of preterm infants, and infants born before 32 weeks of gestation are at greater risk. ${ }^{2,3,11}$

Most of the relevant research has focused on the cognitive development outcomes of preterm infants. ${ }^{6,17-20}$ Only a few studies have investigated the relationship between the motor and sensory development of preterm infants in the first year of life, and the available results are conflicting..$^{3,8,21,22}$ Celik et al. ${ }^{21}$ indicated that there is a significant association of gross motor function with sensory processing among infants born prematurely at corrected ages of 10-12 months, whereas Cabral et al. ${ }^{8}$ could not find any relationship between motor function and sensory processing in premature infants at 4-6 months old.

In a recent study, de Paula Machado et al. ${ }^{4}$ investigated the relationship between motor development, cognitive development, and sensory processing at the age of 12 months. ${ }^{4}$ They indicated that early birth adversely affected sensory processing, and ocular-motor control in sensory processing was positively correlated with motor development. ${ }^{4}$ However, they only provide insight into sensory processing and prematurity at the age of 12 months. The main possible reasons for these inconsistent results are the cross-sectional design of the studies and the heterogeneity of the sample groups. Myelinization begins in the $2^{\text {nd }}$ trimester continues during the first year of life. ${ }^{23}$ Therefore, observing motor and sensory development prospectively is clinically important for determining difficulties in sensory processing and motor delay in the first year of life, which is crucial for referral to necessary early interventions. ${ }^{24}$

There is quite limited research on sensory processing disorder during the first year of life in infants born preterm. ${ }^{4,11,22}$ Furthermore, there is an essential need to focus on this subject in prospective studies. Thus, the aim of this study was to determine the association of sensory processing with motor development among infants born very preterm with developmental delay and very preterm infants who had typical development. We hypothesized that preterm infants with developmental delay would have poorer sensory processing and motor performance than preterm infants with typical development. We also hypothesized there is a relationship between improved fine and gross motor outcomes and better sensory processing.

\section{Material and Methods}

Approval for this prospective study was obtained from the Ethics Committee of the University of Health Sciences, NonInterventional Clinical Researches Ethics Board Project No: 18/250). The families included were informed about the study, and the necessary permission was obtained with signed informed consent forms. The Declaration of Helsinki was applied in the study process.

\section{Participants}

We recruited 78 very preterm infants who were treated at a university hospital in the 
department of pediatric neurology between October 2018 and March 2019. The inclusion criteria for infants in the preterm delayed group included (1) gestational age of 32 weeks or less and a current corrected age of 8 months; (2) having spent at least 15 days in the NICU; and (3) a diagnosis of developmental delay by a pediatric neurologist and child and adolescent psychiatrist according to clinical evaluation and the Denver Developmental Screening Test-II. ${ }^{25}$ The inclusion criteria for the preterm comparison group were (1) gestational age of 32 weeks or less and a current corrected age of 8 months; (2) having spent at least 15 days in the NICU; and (3) normal motor development based on the Denver Developmental Screening Test-II. ${ }^{25}$ Infants were excluded from the study if they had any congenital abnormalities, genetic syndromes, musculoskeletal disorders, or hearing or visual impairment.

Of the 78 participants, 36 were assigned to the preterm delayed group (preterm infants with developmental delay), and 42 were assigned to the preterm comparison group (preterm infants with normal development), after dropouts which have been shown in Fig. 1, 33 infants in the preterm delayed group and 28 infants in the preterm comparison group completed all the assessments.

\section{Procedures}

Approximately two hours after feeding, standardized assessments were performed on a large mattress on the floor or on a table with the infant in a sitting position on the mother's lap. The infants did not take any medication that would interfere with the assessment. The Neuro-sensory Motor Developmental Assessment (NSMDA) and the Test of Sensory Functions in Infants (TSFI) were used for the evaluations, which each took approximately 20 minutes. The NSMDA and TSFI tests were applied to infants at corrected ages of 8 and 12 months. The NSMDA was applied by the first author, who had 10 years of experience in the field of pediatric rehabilitation. The TSFI was applied by the second author, who had nine years of experience in pediatric rehabilitation.

\section{Neuro-Sensory Motor Developmental Assessment (NSMDA)}

The NSMDA consists of six sections that evaluate the movement function of children at 1 month to 6 years of age. It is a criterionreferenced test, and the categories evaluated are age-appropriate: (1) gross motor function, (2) fine motor function, (3) neurological status, (4) infant patterns of movement, (5) posture and balance, and (6) sensory-motor function. The scores of these six areas are summed to calculate a neurosensory motor developmental score. Development in each section is given points ranging from 1 (within normal limits) to 5 (no independent function). The scores of each section are summed to obtain functional grade scores for the motor performance classification of infants.

Total functional grade scores of 6-8 on the NSMDA were classified as normal motor function, scores of 9-11 indicated minimal motor problems, scores of 12-13 indicated mild motor problems, scores of 14-19 indicated moderate motor problems, scores of 20-25 indicated severe motor dysfunction, and scores of $>25$ indicated profound motor dysfunction. The biggest advantage of the NSDMA is its ability to differentiate between normal motor function and minimal, mild, moderate, or severe motor dysfunction. ${ }^{26,27}$ The psychometric properties of the NSMDA have been identified for preterm ${ }^{28,29}$ and extremely low-birth-weight infants. ${ }^{30}$

\section{Test of Sensory Functions in Infants (TSFI)}

The TSFI assesses the disturbances of sensorimotor integration that have a risk of occurrence in children aged $4-18$ months. The TSFI consists of five subtests and 24 items that assess the functioning of the basic senses by observing the following features: sensitivity to deep pressure, the level of adaptive motor functions, visual-tactile coordination, control of eye movements, and the level of integration 


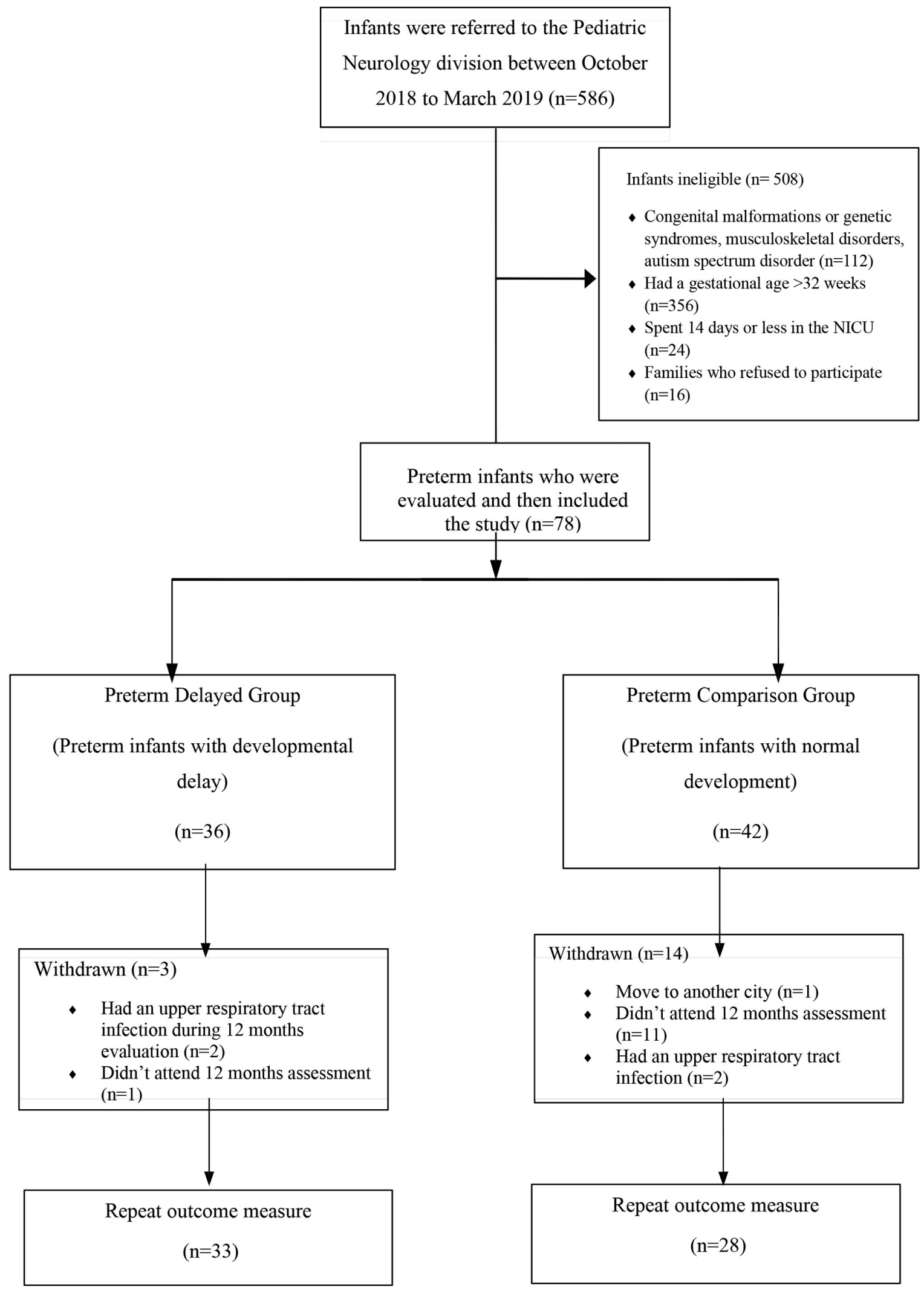

Fig. 1. Follow-up diagram. 
of vestibular information. The range of the total score is 0 to 49 , and higher scores show improved sensory processing.

The TSFI has cutoff values of four different age groups for both the subtests and the total score according to norm-referenced values of North American infants with typical development. Based on the cutoff values, sensory processing skills are evaluated as normal, risky, or abnormal. ${ }^{31}$ Worldwide, the sensory processing of infants is usually assessed with the TSFI. It has commonly been used to determine the difficulties in sensory processing in preterm infants by Turkish researchers, ${ }^{21}$ but a validation study for the Turkish population has not been performed yet. ${ }^{32}$

\section{Statistical analysis}

Statistical analyses were performed using the software SPSS version 21 for macOS (IBM SPSS Statistics; IBM Corporation, Armonk, NY, USA). The number of individuals needed in the study was determined to be 30 according to a power analysis using $\alpha=0.05$ and $\beta=0.20$ (for $80 \%$ power). ${ }^{21}$ The conformity of the variables to a normal distribution was determined by the Kolmogorov-Smirnov test along with histogram and box plots.
Descriptive statistics of the data were calculated with the mean and standard deviation. MannWhitney's U-test was used to describe the differences between groups at the ages of 8 and 12 months in the NSMDA sub-parameters and TSFI results. The relationship between the NSMDA and TSFI results of the preterm infants was analyzed with the Spearman correlation test. In the evaluation of the relationship, the correlation coefficients were classified as follows: $0-0.24$ : weak, $0.25-0.49$ : moderate, $0.50-0.74$ : strong, $0.75-1.00$ : very strong ${ }^{33} \cdot \mathrm{p}$ $<0.05$ was considered as statistically significant.

\section{Results}

The characteristics of the preterm infants are presented in Table I. There were no statistical differences between the groups. Baseline data showed that each group was well matched, including gestational age, birth weight, gender, maternal age, days in the neonatal care unit, etc.

Table II shows the median NSMDA and TSFI scores of the preterm infants and the differences at corrected ages of 8 and 12 months for each group. Compared to the average normal scores of the NSMDA subdomains, the preterm infants in the preterm delayed group showed decreases

Table I. Characteristics of the preterm infants.

\begin{tabular}{lccc}
\hline Characteristics & $\begin{array}{c}\text { Preterm delayed } \\
\text { group }(\mathrm{n}=33)\end{array}$ & $\begin{array}{c}\text { Preterm comparison } \\
\text { group }(\mathrm{n}=28)\end{array}$ & $\mathrm{p}$ \\
\hline Gestational age (weeks) & Mean (SD) & Mean (SD) & $29.3(1.7)$ \\
Birth weight (g) & $28.9(2.3)$ & $1225.28(258.2)$ & 0.46 \\
Corrected age (d) in first assessment & $1154.66(318.14)$ & $242.89(4.8)$ & 0.35 \\
Maternal age (y) & $241.9(2.8)$ & $32.6(4.4)$ & 0.22 \\
Days on Neonatal Intensive Care Unit & $31.09(5.07)$ & $24.21(6.08)$ & 0.87 \\
& $23.93(7.18)$ & $\mathrm{n}(\%)$ & 0.2 \\
Gender (Males/Females) & $\mathrm{n}(\%)$ & $17(60.7) / 11(39.3)$ & 0.11 \\
Multiple births & $11(50.8) / 30(49.2)$ & $14(50)$ & 0.29 \\
Respiratory distress syndrome & $9(27.3)$ & $9(32.1)$ & 0.11 \\
Bronchopulmonary dysplasia & $16(48.5)$ & 0 & 0.37 \\
Intraventricular haemorrhage I/II & $4(12.1)$ & $8(28.6)$ &
\end{tabular}

Mann-Whitney's U-test for continuous variables and the Chi-square test for categorical variables. 
Table II. Neurosensory Motor Developmental Assessment (NSMDA) and Test of Infant Sensory Profile Scores (TSFI) at 8-12 months corrected age

\begin{tabular}{|c|c|c|c|c|c|c|c|c|}
\hline \multirow[b]{2}{*}{ NSMDA } & \multicolumn{2}{|c|}{$\begin{array}{l}\text { Preterm delayed } \\
\text { group } \\
(\mathrm{n}=33)\end{array}$} & \multicolumn{2}{|c|}{$\begin{array}{l}\text { Preterm comparison } \\
\text { group } \\
(\mathrm{n}=28)\end{array}$} & \multicolumn{2}{|c|}{$\begin{array}{l}\text { Differences } \\
\text { between } \\
\text { groups at } 8 \\
\text { months }^{\mathrm{a}}\end{array}$} & \multicolumn{2}{|c|}{$\begin{array}{l}\text { Differences } \\
\text { between } \\
\text { groups at } 12 \\
\text { months }^{\mathrm{a}}\end{array}$} \\
\hline & $\begin{array}{l}8 \text { months } \\
\text { Median } \\
(25 \%-75 \%)\end{array}$ & $\begin{array}{l}12 \text { months } \\
\text { Median } \\
(25 \%-75 \%)\end{array}$ & $\begin{array}{l}8 \text { months } \\
\text { Median } \\
(25 \%-75 \%)\end{array}$ & $\begin{array}{l}12 \text { months } \\
\text { Median } \\
(25 \%-75 \%)\end{array}$ & Z & p & Z & $\mathrm{p}$ \\
\hline $\begin{array}{l}\text { Gross motor } \\
\text { (Mean average score for } 8 \\
\text { months }=30 \text {, for } 12 \text { months }=24 \text { ) }\end{array}$ & $\begin{array}{c}15 \\
(11-22)\end{array}$ & $\begin{array}{c}17 \\
(12-21)\end{array}$ & $\begin{array}{c}32.5 \\
(31-36.5)\end{array}$ & $\begin{array}{c}31 \\
(27.25-31)\end{array}$ & -6.68 & $<0.001$ & -5.86 & $<0.001$ \\
\hline $\begin{array}{l}\text { Fine Motor } \\
\text { (Mean average score for } 8 \\
\text { months }=15 \text {, for } 12 \text { months }=15 \text { ) }\end{array}$ & $\begin{array}{c}10 \\
(6.5-12.5)\end{array}$ & $\begin{array}{c}11 \\
(9-13)\end{array}$ & $\begin{array}{c}19.5 \\
(16-20)\end{array}$ & $\begin{array}{c}16.5 \\
(15-20)\end{array}$ & -6.7 & $<0.001$ & -5.73 & $<0.001$ \\
\hline $\begin{array}{l}\text { Tactile } \\
\text { (Mean average score for } 8 \\
\text { months }=12 \text {, for } 12 \text { months }=12 \text { ) }\end{array}$ & $\begin{array}{c}4 \\
(4-9)\end{array}$ & $\begin{array}{c}8 \\
(4-9.5)\end{array}$ & $\begin{array}{c}12 \\
(12-16)\end{array}$ & $\begin{array}{c}12 \\
(12-16)\end{array}$ & -6.71 & $<0.001$ & -5.34 & $<0.001$ \\
\hline $\begin{array}{l}\text { Ocular } \\
\text { (Mean average score for } 8 \\
\text { months }=12 \text {, for } 12 \text { months }=9 \text { ) }\end{array}$ & $\begin{array}{c}6 \\
(4-7)\end{array}$ & $\begin{array}{c}8 \\
(5.5-9)\end{array}$ & $\begin{array}{c}12 \\
(12-12)\end{array}$ & $\begin{array}{c}12 \\
(10-12)\end{array}$ & -6.75 & $<0.001$ & -5.72 & $<0.001$ \\
\hline $\begin{array}{l}\text { Vestibular } \\
\text { (Mean average score for } 8 \\
\text { months }=12 \text {, for } 12 \text { months }=12 \text { ) }\end{array}$ & $\begin{array}{c}6 \\
(4-8)\end{array}$ & $\begin{array}{c}8 \\
(4-9)\end{array}$ & $\begin{array}{c}12 \\
(12-12)\end{array}$ & $\begin{array}{c}12 \\
(12-12)\end{array}$ & -7.0 & $<0.001$ & -5.32 & $<0.001$ \\
\hline $\begin{array}{l}\text { Functional Level } \\
\text { (Normal=5-8) }\end{array}$ & $\begin{array}{c}15 \\
(10-26)\end{array}$ & $\begin{array}{c}17 \\
(9-26)\end{array}$ & $\begin{array}{c}6 \\
(6-7)\end{array}$ & $\begin{array}{c}7 \\
(7-7.75)\end{array}$ & -6.75 & $<0.001$ & -5.94 & $<0.001$ \\
\hline TSFI & & & & & & & & \\
\hline $\begin{array}{l}\text { Response to tactile deep } \\
\text { pressure } \\
(\text { Normal=9-10) }\end{array}$ & $\begin{array}{c}4 \\
(2.5-8)\end{array}$ & $\begin{array}{c}7 \\
(4-8)\end{array}$ & $\begin{array}{c}10 \\
(9-10)\end{array}$ & $\begin{array}{c}9.5 \\
(9-10)\end{array}$ & -6.63 & $<0.001$ & -5.79 & $<0.001$ \\
\hline $\begin{array}{l}\text { Adaptive motor functions } \\
\text { (Normal=14-15) }\end{array}$ & $\begin{array}{c}5 \\
(4-12)\end{array}$ & $\begin{array}{c}12 \\
(4-13)\end{array}$ & $\begin{array}{c}14 \\
(14-15)\end{array}$ & $\begin{array}{c}14 \\
(14-14.75)\end{array}$ & -6.62 & $<0.001$ & -5.71 & $<0.001$ \\
\hline $\begin{array}{l}\text { Visual-tactile integration } \\
\text { (Normal=9-10) }\end{array}$ & $\begin{array}{c}4 \\
(2-7)\end{array}$ & $\begin{array}{c}6 \\
(3-7.5)\end{array}$ & $\begin{array}{c}9 \\
(9-10)\end{array}$ & $\begin{array}{c}9 \\
(9-9)\end{array}$ & -6.63 & $<0.001$ & -5.78 & $<0.001$ \\
\hline $\begin{array}{l}\text { Oculomotor control } \\
(\text { Normal=2) }\end{array}$ & $\begin{array}{c}0 \\
(0-1)\end{array}$ & $\begin{array}{c}1 \\
(0-1)\end{array}$ & $\begin{array}{c}2 \\
(2-2)\end{array}$ & $\begin{array}{c}2 \\
(2-2)\end{array}$ & -7.0 & $<0.001$ & -6.07 & $<0.001$ \\
\hline $\begin{array}{l}\text { Response to vestibular stimuli } \\
\text { (Normal=10-12) }\end{array}$ & $\begin{array}{c}4 \\
(3-9)\end{array}$ & $\begin{array}{c}8 \\
(4-9)\end{array}$ & $\begin{array}{c}11 \\
(10-11)\end{array}$ & $\begin{array}{c}10 \\
(10-10.75)\end{array}$ & -6.53 & $<0.001$ & -5.78 & $<0.001$ \\
\hline $\begin{array}{l}\text { TSFI total score } \\
\text { (Normal }=44-49 \text { ) }\end{array}$ & $\begin{array}{c}17 \\
(11.5-37.5)\end{array}$ & $\begin{array}{c}34 \\
(14.5-40)\end{array}$ & $\begin{array}{c}46 \\
(45-47)\end{array}$ & $\begin{array}{c}45 \\
(44-46.75)\end{array}$ & -6.52 & $<0.001$ & -5.83 & $<0.001$ \\
\hline
\end{tabular}

aMann-Whitney's U-test, * $\mathrm{p}<0.05$, NSMDA: neurosensory motor developmental assessment, TSFI: test of infant sensory profile scores

of $50 \%$ in gross motor scores (30 versus 15$)$, $33.3 \%$ in fine motor scores (15 versus 10 ), $66.6 \%$ in tactile scores (12 versus 4 ), $50 \%$ in ocular scores (12 versus 6$)$, and $50 \%$ in vestibular scores (12 versus 6) at 8 months. At 12 months, the preterm delayed group's subdomain scores 
showed decreases of $29.1 \%$ in gross motor scores (24 versus 17), $26.6 \%$ in fine motor scores (15 versus 11$), 33.3 \%$ in tactile scores (12 versus 8 ), $33.3 \%$ in ocular scores, and $33.3 \%$ in vestibular scores (12 versus 8 ) compared to the average normal scores.

In the preterm comparison group, the median scores of the NSMDA subdomains were in the normal range at 8 and 12 months. The median functional level indicated moderate motor problems for the preterm delayed group and normal motor function for the preterm comparison group at the ages of 8 and 12 months. The median TSFI total and subdomains scores were classified as risky-abnormal for the preterm delayed group and normal for the preterm comparison group at 8 and 12 months. There were also significant differences in the NSMDA subdomains and functional levels, TSFI subdomains, and the total TSFI score between the preterm delayed and preterm comparison groups at corrected ages of 8 and 12 months $(\mathrm{p}<0.001)$.

According to the NSMDA functional level score, 13 preterm infants were classified as having minimal-mild motor problems, and 20 had moderate to profound motor problems at the corrected age of 8 months. Based on the total scores of TSFI, 7 infants were in the risky group, and 27 were in the abnormal group at 8 months. At the corrected age of 12 months, the NSMDA indicated that 14 preterm infants were classified as having minimal-mild motor problems, and 19 had moderate to profound motor problems. Based on the total scores of TSFI, 8 infants were in the risky group, and 26 were in the abnormal group. Table III shows the classification of motor and sensory levels of the infants born very preterm.

There was a very strong positive correlation between the gross and fine motor scores of the NSMDA and the NSMDA sensory subdomains (tactile, vestibular, and ocular). Furthermore, there were very strong positive correlations between gross and fine motor scores of the NSMDA and the total and subdomain scores of the TSFI. There were very strong negative correlations between the functional level according to the NSMDA, the NSMDA subdomains, and the TSFI's total and subdomain scores ( $p<0.001$; Table IV, Fig. 2).

\section{Discussion}

This prospective study investigated the correlation of motor development with sensory processing at the ages of 8 and 12 months among infants born very preterm. The results show that very preterm infants with developmental delay were in the risky-abnormal group of sensory processing and had moderate motor problems in motor development. In addition, there were very strong positive correlations between gross and fine motor function development and sensory processing at the ages of 8 and 12 months in infants born very preterm. Particularly, there were very strong negative correlations between sensory processing and motor performance.

Research indicates that very preterm infants have a higher risk of neurosensory motor disorders than their term-born peers. ${ }^{34}$ Pin et

Table III. Classifications of motor and sensory level of preterm infants.

\begin{tabular}{lccc}
\hline $\begin{array}{l}\text { NSMDA } \\
\text { Functional level N }(\%)\end{array}$ & Normal & $\begin{array}{c}\text { Minimal-mild } \\
\text { motor problems }\end{array}$ & Moderate-profound \\
\hline 8 months & $28(45.9)$ & $13(21.3)$ & $20(32.8)$ \\
12 months & $28(45.9)$ & $14(23)$ & $19(31.1)$ \\
TSFI total score N (\%) & Normal & Risky & Abnormal \\
8 months & $27(44.3)$ & $7(11.5)$ & $27(44.3)$ \\
12 months & $27(44.3)$ & $8(13.1)$ & $26(42.6)$ \\
\hline
\end{tabular}

NSMDA: neurosensory motor developmental assessment, TSFI: test of infant sensory profile scores 
Table IV. Relationship between NSMDA and TSFI scores.

\begin{tabular}{|c|c|c|c|c|c|c|c|c|c|c|c|c|}
\hline \multirow{3}{*}{ NSMDA } & \multicolumn{4}{|c|}{ Gross motor } & \multicolumn{4}{|c|}{ Fine motor } & \multicolumn{4}{|c|}{ Functional level } \\
\hline & \multicolumn{2}{|c|}{$8 \mathrm{mo}$} & \multicolumn{2}{|c|}{$12 \mathrm{mo}$} & \multicolumn{2}{|c|}{$8 \mathrm{mo}$} & \multicolumn{2}{|c|}{$12 \mathrm{mo}$} & \multicolumn{2}{|c|}{$8 \mathrm{mo}$} & \multicolumn{2}{|c|}{$12 \mathrm{mo}$} \\
\hline & $\mathrm{r}$ & $\mathrm{p}$ & $\mathrm{r}$ & $\mathrm{p}$ & $\mathrm{r}$ & $\mathrm{p}$ & $\mathrm{r}$ & $\mathrm{p}$ & $\mathrm{r}$ & $\mathrm{p}$ & $\mathrm{r}$ & $\mathrm{p}$ \\
\hline Tactile & 0.93 & $<0.001$ & 0.83 & $<0.001$ & 0.90 & $<0.001$ & 0.82 & $<0.001$ & -0.92 & $<0.001$ & -0.84 & $<0.001$ \\
\hline Ocular & 0.89 & $<0.001$ & 0.82 & $<0.001$ & 0.88 & $<0.001$ & 0.87 & $<0.001$ & -0.90 & $<0.001$ & -0.93 & $<0.001$ \\
\hline Vestibular & 0.93 & $<0.001$ & 0.92 & $<0.001$ & 0.90 & $<0.001$ & 0.82 & $<0.001$ & -0.93 & $<0.001$ & -0.84 & $<0.001$ \\
\hline TSFI & & & & & & & & & & & & \\
\hline $\begin{array}{l}\text { Response to tactile } \\
\text { deep pressure }\end{array}$ & 0.91 & $<0.001$ & 0.85 & $<0.001$ & 0.88 & $<0.001$ & 0.85 & $<0.001$ & -0.89 & $<0.001$ & -0.89 & $<0.001$ \\
\hline $\begin{array}{l}\text { Adaptive motor } \\
\text { functions }\end{array}$ & 0.92 & $<0.001$ & 0.89 & $<0.001$ & 0.89 & $<0.001$ & 0.85 & $<0.001$ & -0.90 & $<0.001$ & -0.91 & $<0.001$ \\
\hline $\begin{array}{l}\text { Visual-tactile } \\
\text { integration }\end{array}$ & 0.91 & $<0.001$ & 0.92 & $<0.001$ & 0.89 & $<0.001$ & 0.90 & $<0.001$ & -0.90 & $<0.001$ & -0.94 & $<0.001$ \\
\hline Oculomotor control & 0.88 & $<0.001$ & 0.92 & $<0.001$ & 0.87 & $<0.001$ & 0.88 & $<0.001$ & -0.89 & $<0.001$ & -0.92 & $<0.001$ \\
\hline $\begin{array}{l}\text { Response to } \\
\text { vestibular stimuli }\end{array}$ & 0.92 & $<0.001$ & 0.89 & $<0.001$ & 0.87 & $<0.001$ & 0.87 & $<0.001$ & -0.89 & $<0.001$ & -0.92 & $<0.001$ \\
\hline Total score & 0.93 & $<0.001$ & 0.88 & $<0.001$ & 0.89 & $<0.001$ & 0.87 & $<0.001$ & -0.90 & $<0.001$ & -0.90 & $<0.001$ \\
\hline
\end{tabular}

NSMDA: neurosensory motor developmental assessment, TSFI: test of infant sensory profile

al. ${ }^{35}$ showed that at 8 months, preterm infants exhibit similar movements to their term-born peers in prone and supine positions. However, there were significant differences between them in motor performance in sitting and standing postures, which require more muscle activation and motor control against gravity.

Olsen et al. ${ }^{36}$ investigated the neurodevelopmental results of 137 preterm infants at the age of 12 months who were born before 30 weeks of gestation. They demonstrated that the functional level of $76.6 \%$ of preterm infants was classified as mild to severe motor dysfunction according to the NSMDA. Similarly, the gross and fine motor scores of preterm infants with developmental delay in our study were below the average normal score. In addition, 33\% of preterm infants in our study were classified as having minimal to profound motor dysfunction according to the functional level. Preterm infants have a higher risk for motor problems, so a multidisciplinary team approach in the NICU is crucial to detect and follow-up these preterm infants with motor delay and educate the family in an early period, especially in developing countries.
During the first year of life, the accuracy of neuromotor assessments is conflicting because motor development is not only fast and comprehensive but is also influenced by biological, environmental, and social factors. Burns et al. ${ }^{26}$ indicated that the 8th month is the best evaluation month to predict normal or abnormal motor development in infants. Delays in gross and fine motor development could thus occur with increasing age. Therefore, in this prospective study, preterm infants were first assessed at 8 months to obtain information about motor performance and sensory processing about infants born very preterm.

Preterm infants are at high risk for sensory development from exposure to adverse sensory feedback, such as long-term intubation, heellance procedures, and intense sounds and lights in the NICU, as opposed to the safe environment of the uterus. Ryckman et al. ${ }^{3}$ investigated sensory processing disorder in preterm infants born at 30 weeks or earlier when they had reached the age of 4-6 years. They demonstrated that $50 \%$ of the children had sensory processing disorder. 

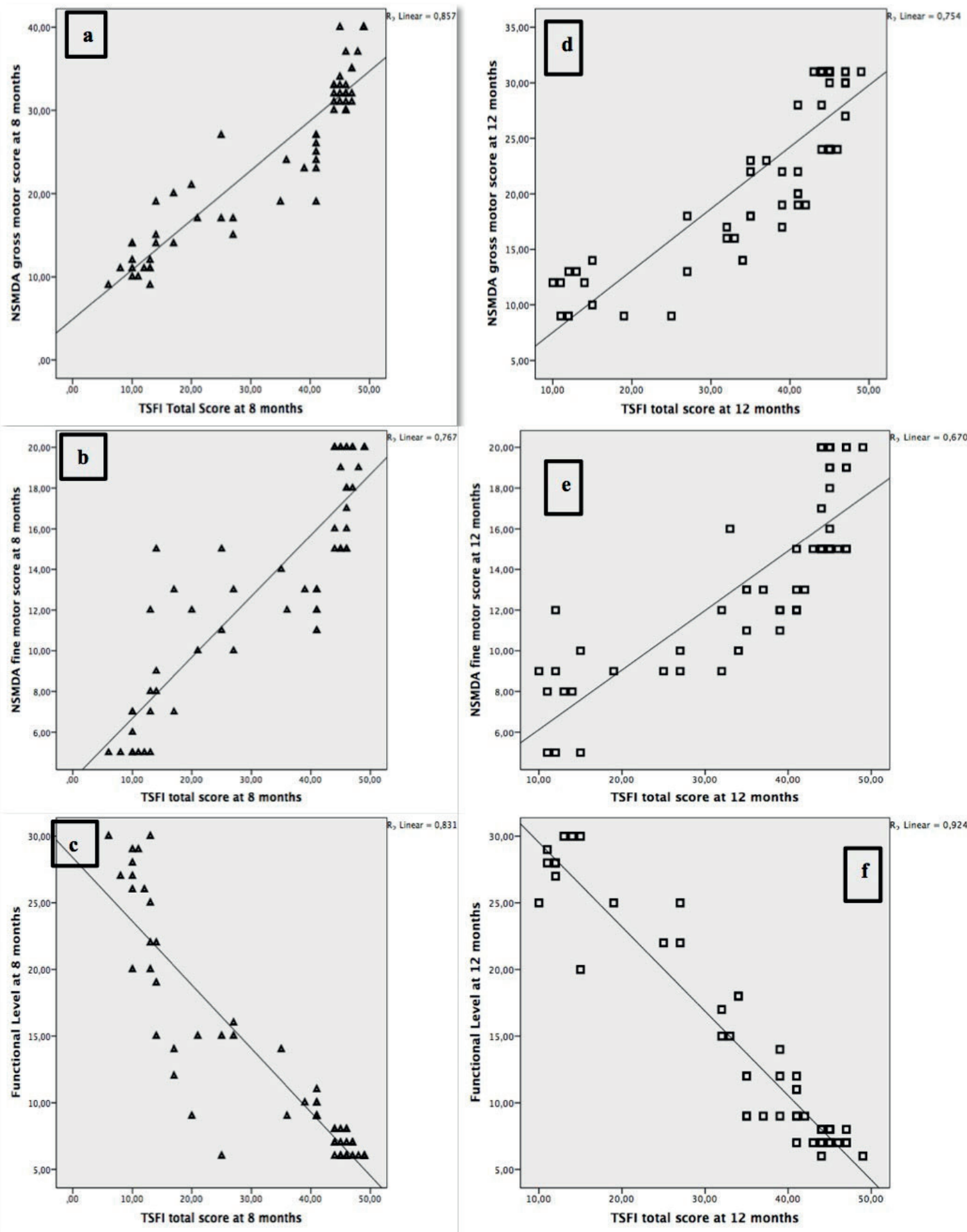

Fig. 2. (a, b, c) Relationship between gross motor, fine motor, and total TSFI scores at 8 months, (d, e, f) Relationship between gross motor, fine motor, and total TSFI scores at 12 months. 
Similarly, Chorna et al. ${ }^{22}$ found abnormal sensory reactivity at 12 months of age in $82 \%$ of infants born with weights of 1500 grams or less. Cabral et al. $^{8}$ showed significant differences in tactile deep pressure perception between term and preterm infants born at 37 weeks of gestation or earlier who stayed in the NICU for at least one day. Celik et al. ${ }^{21}$ showed that there was a risk of sensory development issues in $60 \%$ of infants at the ages of 10-12 months who were born at 37 weeks or earlier and stayed in the NICU for at least 15 days.

The current study investigated the sensory processing of very preterm infants at the ages of 8 and 12 months. Similar to the literature, the TSFI indicated that infants born very preterm in this study had a higher risk in terms of oculomotor control, response to tactile deep pressure, visual-tactile integration, adaptive motor functions, and response to vestibular stimuli at the ages of 8 and 12 months. Furthermore, $44.3 \%$ of them at 8 months and $42.6 \%$ of them at 12 months had abnormal sensory processing. Findings from a recent study by de Paula Machado et al. ${ }^{4}$ support our results in that there was a negative correlation between premature birth and sensory processing.

It is not surprising to observe the adverse effects of daily stressors in the NICU among preterm infants. NICU professionals should be aware of the increasing risk of sensory processing difficulties in preterm infants. In addition, neonatologists could improve strategies with physiotherapists and occupational therapists to prevent sensory processing problems during the first year of life, when cerebral plasticity is greater.

A few studies have investigated the relationship between motor development and sensory processing. Cabral et al. ${ }^{8}$ indicated that $53 \%$ of preterm infants at the ages of 4-18 months had a risk of gross motor developmental delays. However, they did not show a statistically significant association between motor function development and sensory processing. A possible reason for this might be that they included preterm infants born at 37 weeks or earlier who stayed in the NICU for at least one day. Chorna et al. ${ }^{22}$ showed that preterm infants who had abnormal reactivity at 12 months also had worse motor and language developmental scores than preterm infants who had normal reactivity at 12 months. Celik et al. ${ }^{21}$ did a cross-sectional study that demonstrated a strong, significant, positive relationship between gross motor function and sensory processing in preterm infants at the age of 10-12 months.

In contrast to the literature, the present study prospectively investigated the relationship of motor performance with sensory processing in very preterm infants with developmental delay, along with very preterm infants with typical development at the ages of 8 and 12 months. As a result, we found that there were very strong positive correlations between the TSFI's total and subdomain scores and the NSMDA's fine and gross motor scores. Furthermore, there were very strong negative correlations between the TSFI's total and subdomain scores and functional levels. Recent findings add support to our results that improved sensory processing is related to better motor development at the age of 12 months among infants born preterm and full term. ${ }^{4}$ These results reflect that sensory processing and motor function development are inseparable parts of infant development. In the early rehabilitation process, therapists should take development in its entirety into consideration.

No previous study has investigated the relationship between fine motor development and sensory processing. Our findings showed that there were very strong positive correlations between tactile, ocular, and vestibular processing and fine motor development. Chorna et al. ${ }^{22}$ showed that $21 \%$ of preterm infants had a risk of vestibular issues, $49 \%$ had a risk of tactile issues, and $33 \%$ had a risk of ocular processing issues, which was supported by our results. Similarly, Celik et al. ${ }^{21}$ found a moderate correlation between vestibular and ocular processing and motor development. In light of these findings, rehabilitation approaches that are aimed at 
improving fine motor development should consist of supporting vestibular, ocular, and tactile sensory processing in preterm infants.

There were some limitations to this study. One of them is that no term control group was included. Furthermore, there was no long-term follow-up of the neurodevelopmental outcomes in this cohort. Future studies should determine the association of motor function development with sensory processing. Long-term followup of preterm infants and comparison to term infants should also be conducted.

Preterm infants had a high risk of motor developmental delays and sensory processing disorder. There were very strong relationships between motor function development and sensory processing. The effects of sensorybased early intervention programs for preterm infants should be researched.

\section{Author contribution}

The authors confirm contribution to the paper as follows: study conception and design: ÖKK, SŞ, KK; data collection: ÖKK, SŞ, BK, MA; analysis and interpretation of results: HAT, KK; draft manuscript preparation: ÖKK, HAT. All authors reviewed the results and approved the final version of the manuscript.

\section{Ethical approval}

Approval for this prospectivestudy was obtained from the Ethics Committee of the University of Health Sciences, Non-Interventional Clinical Researches Ethics Board Project No: 18/250).

\section{Source of funding}

The authors have no financial relationships relevant to this article to disclose.

\section{Conflict of interest}

The authors declare that there are no conflicts of interest or funding.

The Turkish Journal of Pediatrics • September-October 2021

\section{REFERENCES}

1. Anderson DE, Patel AD. Infants born preterm, stress, and neurodevelopment in the neonatal intensive care unit: might music have an impact? Dev Med Child Neurol 2018; 60: 256-266.

2. Crozier SC, Goodson JZ, Mackay ML, et al. Sensory processing patterns in children born very preterm. Am J Occup Ther 2016; 70: 7001220050p1-7.

3. Ryckman J, Hilton C, Rogers C, Pineda R. Sensory processing disorder in preterm infants during early childhood and relationships to early neurobehavior. Early Hum Dev 2017; 113: 18-22.

4. de Paula Machado ACC, de Castro Magalhaes L, de Oliveira SR, Bouzada MCF. Is sensory processing associated with prematurity, motor and cognitive development at 12 months of age? Early Hum Dev 2019; 139: 104852.

5. Mitchell AW, Moore EM, Roberts EJ, Hachtel KW, Brown MS. Sensory processing disorder in children ages birth-3 years born prematurely: a systematic review. Am J Occup Ther 2015; 69: 6901220030.

6. Pineda RG, Neil J, Dierker D, et al. Alterations in brain structure and neurodevelopmental outcome in preterm infants hospitalized in different neonatal intensive care unit environments. J Pediatr 2014; 164: 52-60.e2.

7. Victoria NC, Murphy AZ. The long-term impact of early life pain on adult responses to anxiety and stress: historical perspectives and empirical evidence. Exp Neurol 2016; 275(Pt 2): 261-273.

8. Cabral TI, Pereira da Silva LG, Tudella E, Simoes Martinez CM. Motor development and sensory processing: a comparative study between preterm and term infants. Res Dev Disabil 2015; 36C: 102-107.

9. Broring $\mathrm{T}$, Oostrom $\mathrm{KJ}$, Lafeber HN, Jansma EP, Oosterlaan J. Sensory modulation in preterm children: theoretical perspective and systematic review. PLoS One 2017; 12: e0170828.

10. Adams JN, Feldman HM, Huffman LC, Loe IM. Sensory processing in preterm preschoolers and its association with executive function. Early Hum Dev 2015; 91: 227-233.

11. Wickremasinghe AC, Rogers EE, Johnson BC, Shen A, Barkovich AJ, Marco EJ. Children born prematurely have atypical sensory profiles. J Perinatol 2013; 33: 631-635.

12. Cabral TI, da Silva LG, Martinez CM, Tudella E. Analysis of sensory processing in preterm infants. Early Hum Dev 2016; 103: 77-81. 
13. Machado ACCP, Oliveira SR, Magalhaes LC, Miranda DM, Bouzada MCF. Sensory processing during childhood in preterm infants: a systematic review. Rev Paul Pediatr 2017; 35: 92-101.

14. Armstrong DC, Redman-Bentley D, Wardell M. Differences in function among children with sensory processing disorders, physical disabilities, and typical development. Pediatr Phys Ther 2013; 25: 315-321.

15. Hertzog D, Cermak S, Bar-Shalita T. Sensory modulation, physical activity and participation in daily occupations in young children. Can J Occup Ther 2019; 86: 106-113.

16. Bar-Shalita T, Granovsky Y, Parush S, WeissmanFogel I. Sensory Modulation Disorder (SMD) and pain: a new perspective. Front Integr Neurosci 2019; 13: 27.

17. Nosarti C, Giouroukou E, Healy E, et al. Grey and white matter distribution in very preterm adolescents mediates neurodevelopmental outcome. Brain 2008; 131(Pt 1): 205-217.

18. Peterson BS, Vohr B, Staib LH, et al. Regional brain volume abnormalities and long-term cognitive outcome in preterm infants. JAMA 2000; 284: 19391947.

19. Spittle A, Orton J, Anderson PJ, Boyd R, Doyle LW. Early developmental intervention programmes provided post hospital discharge to prevent motor and cognitive impairment in preterm infants. Cochrane Database Syst Rev 2015: CD005495.

20. Orton J, Spittle A, Doyle L, Anderson P, Boyd R. Do early intervention programmes improve cognitive and motor outcomes for preterm infants after discharge? A systematic review. Dev Med Child Neurol 2009; 51: 851-859.

21. Celik HI, Elbasan B, Gucuyener K, Kayihan H, Huri M. Investigation of the Relationship Between Sensory Processing and Motor Development in Preterm Infants. Am J Occup Ther 2018; 72: 7201195020p1-7201195020 p7.

22. Chorna O, Solomon JE, Slaughter JC, Stark AR, Maitre NL. Abnormal sensory reactivity in preterm infants during the first year correlates with adverse neurodevelopmental outcomes at 2 years of age. Arch Dis Child Fetal Neonatal Ed 2014; 99: F475-F479.

23. Vaccarino FM, Ment LR. Injury and repair in developing brain. Arch Dis Child Fetal Neonatal Ed 2004; 89: F190-F192.

24. Kara OK, Sahin S, Yardimci BN, Mutlu A. The role of the family in early intervention of preterm infants with abnormal general movements. Neurosciences (Riyadh) 2019; 24: 101-109.
25. Yalaz K, Epir S. Denver Developmental Screening Test Manual, Standardization for Turkish Children. Ankara: Hacettepe University Press, 1983.

26. Burns YR, Ensbey RM, Norrie MA. The neurosensory motor developmental assessment Part II: predictive and concurrent validity. Aust J Physiother 1989; 35: 151-157.

27. Burns YR, Ensbey RM, Norrie MA. The neurosensory motor developmental assessment Part 1: development and administration of the test. Aust J Physiother 1989; 35: 141-149.

28. Spittle AJ, Lee KJ, Spencer-Smith M, Lorefice LE, Anderson PJ, Doyle LW. Accuracy of two motor assessments during the first year of life in preterm infants for predicting motor outcome at preschool age. PLoS One 2015; 10: e0125854.

29. Spittle AJ, Doyle LW, Boyd RN. A systematic review of the clinimetric properties of neuromotor assessments for preterm infants during the first year of life. Dev Med Child Neurol 2008; 50: 254-266.

30. Danks M, Maideen MF, Burns YR, et al. The longterm predictive validity of early motor development in "apparently normal" ELBW survivors. Early Hum Dev 2012; 88: 637-641.

31. DeGangi GA, Greenspan SI. Test of Sensory Functions in Infants (TSFI) Manual. Los Angeles, CA: Western Psychological Services, 1989.

32. Eeles AL, Spittle AJ, Anderson PJ, et al. Assessments of sensory processing in infants: a systematic review. Dev Med Child Neurol 2013; 55: 314-326.

33. Altman D. Practical Statistics for Medical Research. London: Chapman and Hall, 1992.

34. Raniero EP, Tudella E, Mattos RS. Pattern and rate of motor skill acquisition among preterm infants during the first four months corrected age. Rev Bras Fisioter 2010; 14: 396-403.

35. Pin TW, Darrer T, Eldridge B, Galea MP. Motor development from 4 to 8 months corrected age in infants born at or less than 29 weeks' gestation. Dev Med Child Neurol 2009; 51: 739-745.

36. Olsen JE, Allinson LG, Doyle LW, et al. Preterm and term-equivalent age general movements and 1-year neurodevelopmental outcomes for infants born before 30 weeks' gestation. Dev Med Child Neurol 2018; 60: 47-53. 